International Journal of Scientific Research and Management (IJSRM)

||Volume||09||Issue||06||Pages||EL-2021-1732-1755||2021\|

Website: www.ijsrm.in ISSN (e): 2321-3418

DOI: 10.18535/ijsrm/v9i06.el02

\title{
Academic Motivation And Self- Efficacy As Predictors Of Academic Performance Among Form Three Students In Kitui County, Kenya
}

\author{
Kipngetich Francis Kogei
}

School Of Education

\begin{abstract}
Poor academic performance in national examinations in Kenya like in most countries has been an issue of concern. Poor academic performance has been attributed to school environmental factors with individual psychological factors receiving little attention yet this may contribute towards poor students' academic performance. In addition to this, most of the studies that have explored-psychological factors have been done in developed countries hence leaving a gap locally. The purpose of the study was therefore to examine if self-efficacy and motivation predicts academic performance and if so, to what extent. Academic performance was the outcome variable while the predictor variables was motivation and selfefficacy. The objectives of the study were to examine the relationship between motivation and academic performance, establish the relationship between self-efficacy and academic performance, to determine the relative predictive weights of motivation and self-efficacy on academic performance and lastly to test for gender differences in academic motivation and self-efficacy. Self-determination theory by Ryan and Deci and Social Learning Theory by Bandura guided the study. Data was collected through use of questionnaires which also gave students biographical information. The researcher employed ex post facto design and involved 193 study participants. Out of 31 public secondary schools in Kitui County, 25\% of the schools were sampled for this study. Stratified random sampling procedure was used to select the study sample, 8 schools were selected to participate in the study, and 24 students were randomly selected from each secondary school. A pilot study was carried out on a random sample of 40 students from a public school which was not part of the study sample but of similar characteristics as sampled schools. The academic motivation and academic self-efficacy scales were adapted to measure academic motivation and self-efficacy. Students' academic performance was measured by use of examination records which was obtained from the schools. Pearson product moment correlation coefficient was used to test relationships between variables while multiple regression analysis tests were used to obtain the relative predictive weights of independent variable on outcome variable and t-test for predictor variables for gender. Data was analyzed by use of descriptive and quantitative statistics. This research may be of importance to the educators as they may understand how these psychological predictors may impact on their students. Secondly, the teachers may be able to gauge their students' motivation and self-efficacy which may help them in setting realistic targets for performance. Understanding motivation and self-efficacy may enable schools reach operational efficiency as teachers will be in a position to address students according to their study requirements. In view of the findings, it can be inferred that academic motivation, self-efficacy and academic performance are statistically dependent as the p-value in the ANOVA model was .000 which is less than 0.05, the alpha level of significance for academic and self-efficacy and academic performance $(\mathrm{R}$ $(192)=0.367$. The study recommended that all stakeholders in education should work together in creating conducive environments for development of academic motivation and self-efficacy, among students, and appropriate intervention programmes should be developed in schools, particularly targeting girls in order to help reduce the gender differences which were found to exist with regard to students' academic motivation and self-efficacy learning.
\end{abstract}

\subsection{Introduction}

This chapter describes the background to the study, statement of the problem, purpose of the study, objectives, research questions, limitations and delimitations of the study, assumptions of the study, its significance, theoretical and conceptual framework 


\subsection{Background to the Study}

Globally, academic performance has long been accepted as an important aspect of any education system. In most societies, academic performance has been used as a basis for transition of students from one level to the next, for instance from high school to university. Currently, in the world and Kenya in general, academic performance plays a key role in economic and social development. It is vital to develop and prepare learners for good academic performance of students.

Academic performance gives students a very important and essential opportunity to develop their talents, improve their grades and prepare them for future academic challenges after school. The home serves as the first environment of a learner and as a result, it greatly affects academic performance of learners. The type of family the child is exposed to can greatly influence the child's academic performance. Academic performance has also been used to prepare children for citizenship and to cultivate a highly skilled manpower in readiness for jobs in competitive market, (Kwena, 2007). In Kenya there are two important examinations K.C.S.E and K.C.P.E examinations which are administered by government agencies in collaboration with other stakeholders. The roles of these examinations are diverse and include: acting as regulatory filter to institutions of higher learning, certification and selection of students for careers. It is therefore very important that students pass examinations and attain higher grades thus higher academic performance, (Mutweleli, 2014).

In Kenya, according to KCSE examination essential statistics 2014 and 2015, it is clear that there is a lot of variation in academic performance of students in the Kenya Certificate of Secondary Examination. Many students continue to perform poorly in this examination in spite of them following common syllabus with those they study together within the same class. Learners who perform poorly in examinations are rendered hopeless in life thus engaging in drug abuse and other social malpractices. As a result of poor academic performance, the society stagnate in development. Poor academic performance also leads to failure to achieve academic goals. For instance, when students do examinations, they do them to meet their set academic goals of attaining good grade and doing courses of their choice at the university. This poor academic performance may be attributed to low level of motivation and self-efficacy. Failing in examinations causes failed academic goals. In Kenya, majority of households send their children to primary then secondary schools. Upon attainment of good grades, students can enter the job market or move on to higher training opportunities. Poor academic performance contributes negatively to these.

As learners progress through the secondary school years and approach 15 to 16 years of age, emphasis begins to focus on preparation for the Kenya Certificate of Secondary Education (KCSE) examinations. This has always been considered the most important set of examinations for adolescents by education stakeholders, (Mutweleli, 2014). Whenever the Minister for Education announces Kenya Certificate of Primary Education (KCPE) or Kenya Certificate of Secondary Education (KCSE) examinations results, parents or politicians engage in debate on the causes of poor performance of students in particular regions or schools in the country. The competition for opportunities has led to more pressure being exerted on students by teachers and parents to improve their test scores during school terms in preparation for their KCSE examinations. Students' performance in KCSE in the last two years, 2016 and 2017, has been going down. According to 2016 and 2017 KCSE statistics, out of the 1200 candidates who sat for examination in these two years in Kitui county, only $30 \%$ scored a mean of C+ (plus) and above. Comparing these two years, in each year, approximately $40 \%$ of candidates from the county obtained a mean grade of D+ (plus) and below. Kitui County is among the poor performing counties nationally as per the County Director of Education records on academic performance. This poor performance should worry any stakeholder in education and they have tried to seek answers to the question of mass failure and variation in academic performance. Research has shown that factors such as students' self- esteem, parental involvement and socio-economic status can affect academic performance, (Kathryn, 2013). Poor academic performance is attributed to poor teacher class ratio which overburdens the teacher, (Kwena, 2007). Psychological related factor such as Motivation and Self-efficacy which also contributes to poor academic performance remains unexplored and thus receives less attention.

Motivation is defined as the process that initiates, guides and maintains goal oriented behaviours. 
According to Ajayi, Lawani and Salomi (2012), academic motivation is an important concept in classroom learning and is linked to increased levels of academic performance. A student who is academically motivated is seen as self-determined to succeed in academic work. Levels of motivation vary from one student to another. According to Kwena (2007), one cause of poor academic performance is unattended classes due to low teacher-class ratio which has seen them unable to deliver to their best. Studies by researchers in Kenya on psychological field have focused mainly on self-concept, locus of control and subject attitude as causes of poor performance with Motivation and self-efficacy receiving less attention hence this study

According to Chowdhury and Shahibuddin (2007), there are three types of motivation. First, is intrinsic motivation whereby an individual engages in an activity because of the satisfaction offered by the activity itself. There is also extrinsic motivation which involves a student engaging in an activity to get a reward from his peers and teachers. The third type of motivation is a motivation in which the student may not value his/her work and feels incompetent to perform. Achievement motivation is the subjective, internal and psychological drive, which enables students to pursue what they value, eventually achieving their academic goals. Motivation has been shown to be as an important domain in classroom and is associated with increased levels of academic performance. Students who are motivated are seen to be determined to succeed academically, (Ajayi, Lawani\& Salomi 2012). Research shows that students with higher sense of self efficacy display more of environmental and behavioural determinants of self-regulated learning and thus set higher goals with firm commitment to them. This is a characteristic of learners who are intrinsically motivated and high academic performers.

The other factor that may affect academic performance is self-efficacy which refers to someone's evaluation or judgment of their capabilities to organize and execute courses of action. According to Florentina (2015), self-efficacy is the confidence individuals have in their abilities that they can successfully perform particular tasks. Self-efficacy beliefs vary among individuals, fluctuate under different circumstances, and can change overtime. Among the determinants of self-efficacy, are physiological and emotional states, (Bandura, 1997 \& Simiyu, 2010). A strong sense of self efficacy promotes human accomplishments. For example, a student with high level of self-efficacy works hard and achieves more than one who is less self-efficacious. Selfefficacy may be affected by factors such as mystery experience, modeling and vicarious experience. The interplay between motivation and self-efficacy has been seen to be fundamental in determining academic performance, and lack of academic motivation and self-efficacy may be linked to underperformance.

Researchers have argued out that the resources a student has to use to prepare for examinations and the convenience at which they can access them are key predictors of academic performance. Academic systems seem to focus more on tutorial work and infrastructure. Research has shown that factors such as students' self- esteem, parental involvement and socio-economic status can affect academic performance, (Kathryn, 2013). Poor academic performance is attributed to poor teacher-class ratio which overburdens the teacher, (Kwena, 2007). Researchers have identified some psychological predictors as having more impact on academic performance than others. Performance related studies have shown that internal beliefs are directly related to achievement behaviour, (Kwena, 2007 \& Simiyu, 2010).

There is existing literature on psychological predictors of academic performance but few have been on motivation, self-efficacy and academic performance. Many studies have focused on academic self-concept, defense pessimism, locus of control and academic achievement. In addition, most of these studies have been carried out in developed countries and hence there is need to narrow down the same locally as it would be more productive for educators to have facts from a group they can directly relate with. This study would establish the relationship between motivation, self-efficacy and its impact on academic performance. Kitui County has records of poor academic performance as compared to other parts of Kenya and cannot compare favorably with the national literacy indicators. The general literacy level for the county is at a fair rate of $74.7 \%$, with the Kitui County scoring a bit lower at $18.3 \%$ compared to other parts of the county. This study focuses on academic motivation and self-efficacy as major factors affecting performance of secondary school students. Given the significant impact that self-efficacy can have upon motivation, it is clear that both self-efficacy and motivation go hand in hand. Many researchers have attempted to study certain factors which have been attributed as possible contributors to the variations in academic performances which include: Academic self-concept and resilience (Kwena, 2007; Catteral, 2008; Civite, 2000; Lees 2009). 
According to Ajayi, Lawani and Salomi (2012), academic motivation is a very important concept in day to day classroom learning and is linked to increased levels of academic performance. Students who are academically motivated are seen to be self-determined to succeed in academic work, (Mutweleli, 2014).

\subsection{Statement of the problem}

Poor academic performance among students in national examinations may result to loss of rewarding opportunities to both individual student and the community at large. This may also lead to poor achievement of academic goals and objectives. This poor performance may make many students not to further their studies after KCSE examination and consequently, be unable to undertake their dream careers as a result of poor academic performance. Poor academic performance may also make students frustrated thus engaging in vices like stealing, prostitution and other social misfits to earn a living. It also leads to poor social mobility which lowers the development of the country due to lack of experts in various areas of development who can be attributed to positive social mobility of the country. For this trend to be reversed there is need to understand the factors that can be manipulated to the learners' advantage such as self-efficacy and academic motivation. Few scholars have studied self-efficacy and motivation concurrently and there is need for the two to be studied to evaluate their impact on academic performance. Various researchers in Kenya have attempted to undertake research on causes of poor performance but have focused on defense pessimism, academic concept and self-handicapping. Academic motivation and self-efficacy have received less attention. Yet they have been reported to have a lot of influence on academic performance. The key problem of this study therefore was to develop a prediction equation of academic performance from academic motivation and self-efficacy among form three students in Kitui County, Kenya.

\subsection{Purpose of the study}

The purpose of the study was to establish the relationship between academic motivation and self-efficacy on academic performance, and further examine the relative predictive weights of motivation and self-efficacy on academic performance. The information obtained may be used in guiding learners to develop a construct that can improve academic performance.

\subsection{Objectives of the study}

The objectives of the study were to:

i. Examine the relationship between Academic Motivation and Academic Performance.

ii. Establish the relationship between self-efficacy and academic performance.

iii. Determine the relative predictive weights of motivation and self-efficacy on academic performance.

iv. Test for gender difference in academic motivation and self-efficacy.

\subsection{Research Questions}

i. What is the relationship between academic motivation and academic performance?

ii. How is self-efficacy related to academic performance?

iii. What are the relative predictive weights of motivation and self-efficacy on academic Performance?

iv. What gender difference are there in motivation and Self-efficacy?

\subsection{Significance of the study}

This research study may be of importance to teachers as they may understand how motivation and selfefficacy may impact their students and use it to improve students' academic performance. It is expected that the results of the study may go a long way in improving the academic performance and enhancing competition between learners from Kitui County with those from other counties in Kenya. Through an analysis of a students' strength, a teacher may be in a position to manipulate academic motivation and selfefficacy so as to improve on the performance of the student which in may in turn, improve the overall academic performance. In addition, well performing students may improve school's general performance hence placing it at a good position to compete nationally. Secondly, the results may be used to gauge their students' levels of motivation and self-efficacy which may help education administrators to set realistic targets for performance. 
Understanding academic motivation and self-efficacy as predictors of academic performance may enable schools achieve their set up goals and objectives as teachers may be in a position to address students according to their study requirements. If the recommendations of this research are implemented by the relevant authorities like Kitui county education boards, there may be general improvement in academic performance which has always been an issue of great concern to all education stakeholders in Kitui County. Finally, this study is hoped to serve the universal purpose of research by contributing to the body of knowledge and giving additional knowledge on self-efficacy and academic motivation as predictors psychological predictors of academic performance and trigger interest for more studies on the topic of interest, but in different regions of the country, so as to improve academic performance.

\subsection{Limitations and Delimitations of the study}

\subsubsection{Limitations of the study}

It was not possible to control the attitude exhibited by the respondents as some may want to give socially acceptable answers to please the researcher. Also in the study no control group was used and all items were based on self-reports from respondents, and there might have arose some level of biasness. Data collection was mainly done through questionnaires and academic reports which may have some degree of subjectivity the researcher allowed respondents adequate time to express their views in order to balance subjectivity with objectivity. Although many variables could affect academic performance, this study only dealt with two factors motivation and self-efficacy. Some respondents failed to respond to all items in the questionnaire. Such incomplete responses were excluded during data analysis

\subsubsection{Delimitations of the study}

The study was limited to eight selected public secondary schools in Kitui County and therefore the results might not be generalizable beyond the specific population. The determinants of students' academic motivation and self-efficacy such as home and school environment were not under investigation because the existing literature mainly focused on relationship between academic motivation, self-efficacy and academic performance. The study also dealt with one region (Kitui County) and thus the data generated would be generalized but with caution. All school stakeholders have vital information regarding academic performances in schools; however, respondents to the study were restricted to Principals and Students only.

\subsection{Assumptions of the study}

The study was based on the following assumptions:

i. Academic motivation exists in different levels among the students and can be measured.

ii. $\quad$ Self-efficacy exists in different levels among the students and can be measured.

iii. Homogeneity of learners and schools was assumed.

iv. The records and reports from sampled schools were accurate.

\subsection{Theoretical and Conceptual Framework.}

\subsubsection{Theoretical Framework.}

This research was guided by two theories: Self-determination Theory (SDT) by Ryan and Deci (1997) and Social Learning Theory by Bandura (1986). These two theories will provide a lens through which the researcher will establish whether motivation and self-efficacy influence the general performance of a person and as a result affect academic achievement, how they do so, and to what extent. There is a strong link between the two theories due to the fact that self-determination theory is a theory of motivation and personality that addresses three universal, innate and psychological needs: competence, autonomy, and psychological relatedness; while on the other hand social learning theory gives strong links between performance, motivation, and self-efficacy. Self-efficacy has been shown to be a reliable predictor of both motivation and task performance which influence personal goal setting.

\section{a) Self-determination Theory (Deci and Ryan, 1997).}

This theory was advanced by Deci and Ryan (1997) and sought to explain what prompts people to behave in a certain way towards a certain phenomenon. Self-determination Theory (SDT) is an approach to human motivation and personality that uses traditional empirical methods while employing an organismic metatheory that highlights the importance of humans' evolved inner resources for personality development and behavioural self-regulation. 
The proponents of this theory put a lot of emphasis on motivation of human beings towards the direction and efforts they choose to bestow upon activities. Motivation is affected by many other factors. Motivation refers to the reason of student engagement in a given activity. Students' difference in motivation levels and types can be a reason for the difference in academic performance among learners. In this study, students' motivation may be considered an essential component in teaching and learning process. A student can give his/her best in school because his/her parents require it and the student wants to obey his/her parents. Intrinsically, also the student might have interest and enjoyment in learning and thus the activity is perceived as end in itself thus the student will strive for success.

Academic motivation is therefore a key determinant of academic performance as it is the force that moves a person to act, which also directly contributes to self-efficacy. There is interrelationship between self-efficacy and motivation. Students with higher levels of intrinsic motivation are likely to have higher interest and enjoyment in what they do thus higher academic performance compared to students without or with low intrinsic motivation.

\section{b) Social Learning Theory (Bandura, 1986)}

Bandura's Social Learning Theory emphasizes the interaction between behaviour and environment focusing on behaviour pattern. This theory claims that we learn the way we behave by adapting ourselves to models. Consequently, the child is able to learn how to adapt himself to this new behaviour by watching others do an activity. As Bandura (1997) puts it, self-efficacy refers to personal confidence in one's abilities for successful achievement of various tasks. It is influential factor of whether individuals will be able to expend effort on a task and cope with a difficult situation. Individuals with high levels of self-efficacy attempt tasks and keep trying even though tasks may be difficult, while individual with low levels of self-efficacy give up easily.

The two fundaments based on Bandura's theory are related to the fact that, individual students make personal interpretations of their past achievements and family backgrounds, failing experiences, consequently they set goals. According to this theory, people tend to avoid situations they believe exceed their capacities, but they undertake tasks that they consider themselves capable of accomplishing. The second fundament refers to the fact that students have set individual goals that become their personal standards for assessing their performance for instance on day to day basis learners have their career aspirations in life and they push themselves hard in order to ensure that they achieve their set up goals through academic performance. They use those who have succeeded through education as their motivating factor and they work excellently towards meeting their academic targets to ensure that they succeed in life. Bandura (1997), describe self-efficacy as varying with individuals. It is important to note that two theories were used in the study because the two variables that were used in predicting academic performances though were explained in different theories.

\subsubsection{Conceptual Framework}

The main variables under study were academic motivation, self-efficacy and academic performance. Academic performance of a student can be determined by level of academic performance and self-efficacy. A student who performs well may be seen with higher levels of academic motivation and self-efficacy. Academic motivation is hypothesized to influence academic performance of learners at all levels regardless of their field and age. The other factor to be examined was self-efficacy and its levels. This framework indicates the nature of relationship between the academic motivation, self-efficacy and academic performance. Where the levels of motivation and self-efficacy are high, high academic performance may be expected. Gender will act as the intervening variables because differences in gender may influence predictor variables and consequently the outcome variables.

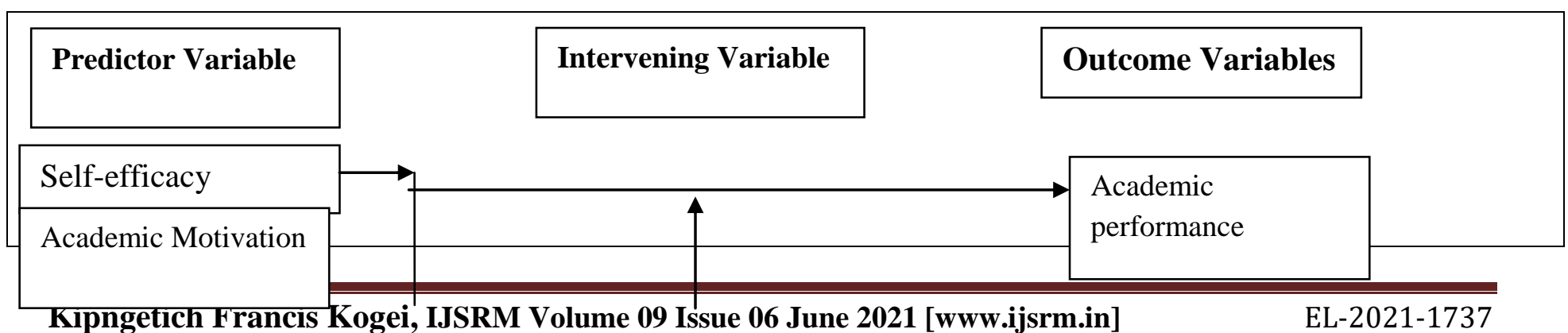


Figure 1.1: Schematic diagram showing the relationship between Academic Motivation, Self-efficacy, Gender and Academic performance

NOTE $\longrightarrow$ Relationship anticipation

$\longleftrightarrow$ Interaction

\subsection{Operational Definition of Terms}

Academic performance this refers to a student's scores as measured by performance tests in

Subjects, continuous assessment tests and end of term or year tests it will be measured at interval level of measurements.

Academic motivation Refers to the process that initiates, guides and maintains goals oriented

behaviours. Measured at interval level of measurements.

Psychological predictors These are factors like motivation and self-efficacy which affect academic performance.

Score

This refers to the mark attained by a student in K.C.S.E and K.C.P.E examination.

Self-efficacy

This refers to personal judgment of one's capability to organize and execute the course of action required to manage prospective situations or produce given attainments, (Florentina, 2015). Measured at interval levels of measurement.

\section{Review Of Related Literature}

\subsection{Introduction}

This chapter examines the existing literature work on academic motivation, self-efficacy and academic performance. This will be done under the following sub-headings: Relationship between academic motivation and academic performance, Relationship between self-efficacy and academic performance, the relative predictive weights of academic motivation and self-efficacy on academic performance, Gender difference in academic motivation and self-efficacy and lastly, summary of literature review and gap identification.

\subsection{Relationship between Academic Motivation and Academic Performance}

A few studies have been found to have directly investigated the relationship between academic motivation, self-efficacy and secondary school academic performance. In a recent study, Matthews, Hoessler, Jonker and Stockley (2013), carried out studies on academic motivation and calculus among engineering students in Canadian universities. To understand the relationship between students' academic performance and motivation, the population was made up of 650 university students. Multiple regressions was used and its findings showed when regression of final scores was done, it was found out that students extrinsically motivated and a motivated learners had lower academic performance. It was observed that intrinsic motivation was a predictor of better exam performance, whereas students with higher intrinsic motivation towards simulation, extrinsic motivation towards introjected regulation, motivation did poorly in examination. Although the findings of this study showed relationship between academic motivation and academic performance, it was carried out among university students. There is need to compare the results 
when secondary students are used. The current study will therefore examine whether motivation and selfefficacy predict academic performance among secondary school students in Kenya using a population of 1930.This difference in population may have confounded the results. Moreover, the study was based on a sample drawn from a developed country and given that Kenya is a developing country, a similar study was needed in order to report on the cross cultural differences. Mutweleli (2014), carried out a study on academic motivation and self-regulated learning as predictors of academic achievement of students in public schools in Nairobi County and found that there was a significant relationship between academic motivation and academic performance. He used a population of 938 students using random, purposive, and simple random sampling procedures. It would be interesting to use a different population thus this study on the relationship between self-efficacy, motivation and academic performance, which will be done in Kitui County with a population of 1930 students using stratified random sampling to compare the results.

In another study, Othman and Leng (2011) tested the relationship between self-concept, intrinsic motivation, self-determination and academic performance. They used a population of 200 students in primary schools in China using questionnaires and the research findings showed negative correlation between variables. This research was done in the East where learning conditions may be different from those in Kenya. Perhaps the results would be different if a different set up and larger sample used to compare the results. The current study which will be done in using a larger of population of 1930 students.

\subsection{Relationship between Self-efficacy and Academic Performance}

According to Florentina (2015), self-efficacy is someone's evaluation or judgment of their capabilities to organize and execute courses of action that are required to attain certain designated types of performances, (Bandura, 2002). Existing literature holds that students with strong academic, self-regulatory and selfefficacy beliefs are more likely to manage their learning. Due to this, students with strong self-efficacy beliefs are usually successful.

According to bandura (2002) students with strong self-efficacy beliefs are usually successful; On the other hand, students who have a low sense of academic self-efficacy to succumb to social pressures hence, jeopardizing their chances of academic success and the outcomes people expect depend heavily on their selfconfidence.

Vance (2012) studied the relationship between mentored field education and self-efficacy in U.S.A, using a population of 102 students from seven seminaries and found out that academic performance was not correlated with self-efficacy. The above study was carried out in seminary where learning is perhaps not as competitive as classroom learning hence self-efficacy may not have affected it significantly. The current study will be carried out in an academic classroom where learning is very competitive. While the above reviewed study was done in USA, the current will be in Kenya which is totally different in terms of geographical, economic, social setups and the findings could fill the gaps that exist in literature.

Chopin, Danish, Seers and Hook (2012), studied the influence of mentoring on development of self-efficacy among leaders. This study used a sample size of 260 graduates. The findings were of higher quality mentoring that led to production of leaders with high self-efficacy. The above study focused on university students but the current study fills this gap in literature by presenting the findings from the students.

\subsection{The Relative Predictive Weights of Academic Motivation and Self-efficacy on Academic Performance}

According to Stevens, Olivarez, Lan and Tallent as cited in Abdelaziz, Alsawaie and Tibi (2012) study on self-efficacy, it was found out that self-efficacy and motivation strongly predicted academic achievement across ethnicity. They carried out their study in United Arab Emirates which is different from Kenya in terms of cultural and geographical set up thus the need for this study to be done in Kenya using a different sample among secondary students to compare the results.

According to Abdelaziz, et al. (2012), there exist a significant correlation between Mathematics self-efficacy and Mathematics motivation effects on academic performance of American undergraduate students and hence made recommendations that self-efficacy and motivation had relatively the same predictive weight on academic performances with motivation and self-efficacy contributing relatively the same percentage, $42 \%$ and $40 \%$ respectively towards academic performance. 
Ajayi (2011) studied the effects of parents occupation, qualification and academic motivation on students' academic achievements in Mathematics. The results indicated that academic motivation had the least effect among the variables. From these results, there was need to further investigate the relative effects on academic performance given academic motivation and other related variables such Chowdhury \& Shahabuddin (2007) studied the effects of self-efficacy, motivation and their relationship to academic performance of College students. There was positive correlation however, the findings were based on college students and it was important to design a similar study among secondary school

\subsection{Gender difference in Academic Motivation and Self-efficacy}

Florentina (2015) carried out a study on influence of E-mentoring on self-esteem, self-efficacy and academic performances among secondary school girls in Nairobi and Kiambu Counties using a population of 277 students and asserts that there is a strong relationship between self-efficacy and academic performance. Urban students were found to have better self-concepts as compared to rural students. In relation to this study, it was considered worth investigating gender differences in the population of drawn from a different environment thus this study.

Shkullaku (2007), in his study outlines the differences in levels of self-efficacy in regard to gender he asserts that female students have lower self-efficacy compared to male students because Albanian society was relatively discriminatory, some sex role stereotypes were very powerful, and as a result females' capacities were undermined by male capacities. Females were found to be internally controlled than males.

\subsection{Summary of Literature Review and Gap Identification}

Their exist much literature on academic motivation and self-efficacy as predictors of academic performance but it is noteworthy that there exists a wide knowledge gap about the way the current study 's predictor and outcome variables interact in Kenya. Many studies were done in different environments rather than secondary schools. Findings of most of the studies had inconsistencies that needed to be addressed. All these created research gaps that needed to be filled addressed.

\section{Research Design And Methodology \\ 3.1 Introduction}

This section gave a detailed description of the research design, research variables, location of the study, target population, sampling techniques and sample size, research instruments, pilot study, validity and reliability of research instruments, data collection techniques, data analysis, logistical and ethical considerations.

\subsection{Research Design}

Ex post facto research design was used in the study. This research design is considered suitable for the study as the predictor variables cannot be manipulated. The designs was ideal for the study as it sought to reveal possible relationships by observing an existing condition and searching back in time for plausible contributing factors. According to Ary, Jacobs, Razavieh and Sovensen (2009), ex post facto research is conducted after variation, when the variable of interest has already been determined in natural course of events. This research design is useful when investigating cause effect relationships between independent and dependent variables in situations which do not permit randomization and manipulation of variables. According to Mutweleli (2014), ex post facto design is categorized into two correlations which will be used in the study and the criterion group study, collection of two sets of data with a view of establishing the relationship between them, reliable for collecting information about people's attitude or any variety on educational issues and on factors that have already occurred.

\subsubsection{Research Variables}

In this study, predictor variables were self-efficacy and academic motivation; the outcome variable was academic performance and the intervening variable was gender. The predictor and the outcome variables were measured at interval level of measurement while gender was at nominal scale of measurement.

\subsubsection{Research Methodology}

The study used two questionnaires: Academic Motivation Scale, Self-efficacy Scale and academic documents which were mainly report forms from the class teachers to collect the data. Demographic data 
was collected using section A of appendix B. Florentina (2015) observe that documents are becoming important primary source for qualitative research and therefore these documents will be considered to have important information for this study.

\subsection{Location of the Study}

The study was carried out in Kitui County. The county has 31 public secondary schools. Kitui County was selected for the study because to the best of the researcher's knowledge, it is among the poorly performing counties in Kenya. In addition, Kitui County was chosen because it is easily accessible to the researcher. Florentina (2015) noted that, the ideal setting for any study should be easily accessible to the researcher and should be that which permits instant rapport with the informants. According to 2017 KCSE examinations statistics, out of the maximum score of (A), Kitui county had a mean score of $\mathrm{C}$ and considering that the university grade for admission into university is $\mathrm{C}+$ (plus). Performance in the county can be considered to be poor.

\subsection{Target Population}

The target population was all Form Threes students in public schools in Kitui County. The accessible population was 193 Form Three students from the sampled public secondary schools in Kitui County (Data was obtained from the Kitui county director of education office as at January, 2019). Form three students were chosen because at the time of this study they had already stayed in secondary schools for a period of about three years and are already focused on subjects that were to be examined at the final examination. The choice of the school was based on the fact that they had presented examination class in the past three KCSE. These schools also had good number of students in form three classes which assisted in meeting the requisite sample and also Form Three are expected to be more serious than any other class.

\subsection{Sampling Technique and Sample Size}

\subsubsection{Sampling Technique}

The study used non-probability and probability sampling techniques. Kothari (2009) defines non-probability sampling as a procedure which does not afford chance for each item in the population to be included in the sample stratified random sampling procedure were used to select the study sample. The study grouped the population into two strata that is; male and female students in Form Three. From each class, simple random sampling was used to select the 193 study participants. Out of 31 public secondary schools in Kitui County, $25 \%$ of the schools were considered for this study. Therefore, 8 schools were involved in the study. The 193 pupils were distributed among the 8 public secondary schools whereby; 24 students were chosen from each secondary school.

\subsubsection{Sample Size}

According to Salvin (1984), due to some factors such as limited time, funds and other logistical constraints, this study was based on carefully selected sample to represent the entire population. The actual sample size of the schools and students who participated in the study were 8 schools and 193 students who were distributed among 8 public secondary schools. In this case, 24 students were sought from each secondary school and who were distributed equally.

Table 3.1: Sample size composition

\begin{tabular}{|l|l|l|}
\hline Respondents & Population & Sample size \\
\hline Boys & 980 & 93 \\
\hline Girls & 950 & 100 \\
Total & 1930 & 193 \\
\hline
\end{tabular}

Source: Researcher (2017) 


\subsection{Research Instruments}

This study used two adopted questionnaires from earlier research on related work and academic documents (report forms) to collect data from students. Mugenda (2007) states that, questionnaires are cheaper to administer to respondents scattered over a larger area. Questionnaires were convenient because of their ability to ensure confidentiality for collecting information from a large population within a short span of time (Mutweleli, 2014). The questionnaire had both open and close ended questions. Structured questions were used in an effort to conserve time as they are in immediate usable form; while the unstructured questions were used to encourage the respondent to give an in-depth and felt response without feeling held back in revealing of any information. 193 questionnaires were administered to Form Three students. Report forms were obtained from the class teachers through the principal.

\subsubsection{Student's Questionnaire}

This questionnaire was divided into three parts: Section A which was used to collect demographic data, B which was the academic motivation scale and $\mathrm{C}$ which was self-efficacy scale for students. (See appendices A, B and C). Students took 15 to 20 minutes filling the questionnaires while seated in class. The questionnaires were filled continuously without a break in between.

\subsubsection{Academic Documents}

The document analyzed were end of Term 2, 2018 results for all participating learners from school records. Test scores of English, Kiswahili, and Mathematics were used since these are the compulsory subjects taken by all students in Kenya. Appendix $\mathrm{C}$ shows the academic document scale which was used to collect data on students' academic performance. Data on academic performance of the students was obtained through document analysis, for the last one year marks (2018) of the respondents from the teacher in charge of academics, and the marks were standardized using T-score formula.

\subsection{Pilot Study}

A pilot study was carried out on a random sample of 40 students from one school among the public schools in Kitui County with similar characteristics as sampled schools. The school were not be part of the study sample. The pilot study was done in order to pretest the instruments to ensure clarity of instructions, questionnaire items and to determine their validity and reliability. It also helped to know whether the allocated time is enough and detect anything ambiguous.

\subsubsection{Validity of the Research Instruments}

Validity of the instruments refers to whether a measure is truthful or genuine; in other words, a measure that is valid assesses what it claims or purports to measure (Florentina, 2015). To enhance face, construct, formative and criterion-related validity of the questionnaire, the questionnaires were presented to researchers from the Department of Educational Psychology, Kenyatta University. The experts assessed whether the instruments captured all the areas under study. This led to adjustment and modification which increased the instrument's validity (Borg \& Gall, 1997).

\subsubsection{Reliability of the Research Instruments}

According to Florentina (2015), reliability deals with how consistently similar measures consistently produce similar results. Self-efficacy was measured using items adapted from Florentina (2015), where reported Cronbach reliability of the questionnaire was at 0.862 for self-efficacy and motivation was found to be at 0.80 . Reliability of instruments was established through administering the questionnaire to the same group of respondents and assessing consistency of performance across the test item (Nsubuga, 2000).

\subsection{Data Collection Techniques}

Questionnaires and academic document were used to collect data. The researcher personally administered the research instruments to the respondents. Students took 15 to 20 minutes filling the questionnaires while seated in class. The questionnaires were filled continuously without a break in between. Academic documents were obtained from the class teacher of the participating classes.

\subsection{Data Analysis}

In analyzing quantitative data, the study used descriptive and quantitative statistics. The following hypotheses were tested: 
$\mathrm{H}_{01}$ : There is no significant relationship between academic motivation and academic performance. Statistical test: Pearson product moment correlation coefficient. This was used because it measures the strength of linear association between data of two variables.

$\mathrm{H}_{02}$ : There is no significant relationship between self-efficacy and academic performance. Statistical test: Pearson product moment correlation because it measures the strength of association between two variables.

$\mathrm{H}_{03}$ : Motivation and Self-efficacy have no significant predictive value on academic performance. Statistical test: Multiple linear regression analysis allows the researcher to determine the overall fit of the model and the relative contribution of each of the predictors to the total variables under study

$\mathrm{H}_{04}$ : There is no Gender difference in academic motivation and self-efficacy. Statistical test: t-test for independent samples. T-test was appropriate because it is a test used to determine differences between two distinct groups, in this case, male and female.

\subsection{Logistical and Ethical Considerations \\ 3.10.1 Logistical considerations}

In order to collect data from the selected schools, the researcher was issued with an introductory letter from the university. A research permit was also obtained from National Commission for Science, Technology and Innovation. The County Education Officer, Kitui, also facilitated collection of data from targeted schools. Clearance to carry out the study was sought from the Ministry of Higher Education. Prior to the commencement of data collection, the researcher, visited the sample schools for familiarization and sensitization purposes.

\subsubsection{Ethical considerations}

The study ensured that participant rights to privacy, confidentiality were maintained. This was by ensuring that information provided was only used for the purpose of the research. This was achieved by providing the respondents with full information about the study in order for them to give their consent (See appendix A).

\section{Findings, Interpretation, And Discussions}

\subsection{Introduction}

This chapter presents the results of the study in various sections starting with response rate, demographic characteristics of the respondents and finally analysis of the study in line with the research objectives that were earlier stated in chapter one.

\subsection{General and demographic information}

\subsubsection{Response rate of research instruments}

Out of the 193 questionnaires issued to students, 192 of them were duly completed and returned thus representing a return rate of about (99.5) while (0.5) of the respondents didn't return the filled questionnaires to the researcher. According to Mugenda and Mugenda (2003) a return rate of any study is considered valid if the rate is above (75.0). This return rate was therefore considered valid.

\subsubsection{Demographic Characteristics of the Respondents}

The demographic characteristics that were of interest to the study included school type, age and gender. Analysis of these characteristics is as shown in the following sections.

\subsubsection{Name of the School}

The participants' name of the school was tabulated and the results are indicated in Table 4.1. Table 4.1: Name of the School

\begin{tabular}{|c|c|c|c|}
\hline Name of the school & Frequency & Valid Percent & Cumulative Percent \\
\hline A & $24(12.5)$ & (12.5) & $(12.5)$ \\
\hline B & $24(12.5)$ & $(12.5)$ & $(25.0)$ \\
\hline $\mathrm{C}$ & $24(12.5)$ & $(12.5)$ & $(37.5)$ \\
\hline $\mathrm{D}$ & $24(12.5)$ & $(12.5)$ & $(50.0)$ \\
\hline $\mathrm{E}$ & $24(12.5)$ & $(12.5)$ & $(62.5)$ \\
\hline
\end{tabular}




\begin{tabular}{|l|l|l|l|}
\hline $\mathrm{F}$ & $24(12.5)$ & $(12.5)$ & $(75.0)$ \\
\hline $\mathrm{G}$ & $24(12.5)$ & $(12.5)$ & $(87.5)$ \\
\hline $\mathrm{H}$ & $24(12.5)$ & $(12.5)$ & $(100.0)$ \\
\hline Total & $\mathbf{1 9 2}(\mathbf{1 0 0 . 0})$ & $\mathbf{( 1 0 0 . 0 )}$ & \\
\hline
\end{tabular}

The data in Table 4.1 shows that each school was represented by 24(12) of the respondents.

\subsubsection{Respondents' Age}

The age distribution across the respondents was as shown in Table 4.3.

Table 4.2: Age of respondents in years

\begin{tabular}{|l|r|r|r|r|}
\hline Age & Frequency & Valid Percent & Cumulative Percent \\
\hline $15-17$ & $123(64.1)$ & $(64.7)$ & $(64.7)$ \\
\hline $18-20$ & $63(32.8)$ & $(33.2)$ & $(97.9)$ \\
\hline $21-25$ & $4(2.1)$ & $(2.1)$ & $(100.0)$ \\
\hline Total & $\mathbf{1 9 0}(\mathbf{1 0 0})$ & $\mathbf{( 1 0 0 . 0 )}$ & \\
\hline
\end{tabular}

Key ( ) is percentages

Table 4.2 shows that majority of the students (64.70) were aged 15 to 17 , followed by 18 to 20 years at (33.20) and 21-25 years at (2.1). From the above data it is noted that the participants in this study were form three students in secondary schools in Kenya. A student, who has gone through the formal education curriculum in Kenya from pre unit where the recommended age for enrollment is for years, is expected to be around sixteen years of age by the time they reach form three. Thus, any student who is above this age and in form three has definitely experienced delay in their schooling. This delay may have been occasioned by a number of factors which includes and not limited to class retention, truancy, sickness, juvenile delinquency, poverty and other factors which may limit the student's academic motivation levels. Those students may have been delayed due to factors like levels of poverty which have negatively impacted on their levels of academic motivation and self-efficacy which has also impacted academic performance negatively. Students experiences and events with academic motivation sources varied due to environment and experiences. Students who exhibited higher academic motivation levels may have been attributed to good family support, particularly from their mothers or someone who fulfilled that motherly role thus high academic performance.

\subsubsection{Sex of the Respondents}

Table 4.3 shows the sex distribution of the respondents.

Table 4.3: Sex of the Respondents

\begin{tabular}{|l|l|l|l|l|}
\hline Sex & Frequency & & Valid Percent & Cumulative Percent \\
\hline Male & $94(49.20)$ & & $(49.20)$ & $(49.20)$ \\
\hline Female & $97(50.80)$ & & $(50.80)$ & $(100.00)$ \\
\hline Total & $\mathbf{1 9 1}$ & $\mathbf{1 0 0 . 0}$ & \\
\hline
\end{tabular}

From the findings, (49.2) were males while (50.8) were females. This implies that there were more male respondents compared to the female respondents.

\subsection{Relationship between Academic Motivation and Academic Performance.}

The first objective of this study sought to establish the relationship between academic motivation and academic performance of students. The response categories were classified into five points showing various levels of agreement namely: CD-completely disagree (1), D-disagree (2), NS-not sure (3), A-agree (4) and CA-completely agree (5). Based on this response scale, the indices of the mean and standard deviation were determined for each statement and were consequently used to report the findings as shown in Table 4.4 


\begin{tabular}{|l|l|l|l|}
\hline & N & Mean & Std. Deviation \\
\hline & 191 & 3.16 & 1.73 \\
\hline & 191 & 4.30 & .94 \\
\hline & 183 & 4.17 & .90 \\
\hline & 185 & 4.36 & .96 \\
\hline & 189 & 3.93 & 1.28 \\
\hline & 188 & 4.31 & .97 \\
\hline & 191 & 4.12 & 1.12 \\
\hline & 186 & 3.05 & 1.65 \\
\hline & 187 & 3.68 & 1.28 \\
\hline & 188 & 4.40 & .96 \\
\hline & 189 & 3.75 & 1.26 \\
\hline & 190 & 4.04 & 1.22 \\
\hline & 187 & 4.48 & .74 \\
\hline & 189 & 4.04 & 1.12 \\
\hline & 179 & 4.28 & 1.05 \\
\hline & 188 & 3.53 & 1.51 \\
\hline & 186 & 2.97 & 1.65 \\
\hline & 185 & 2.44 & 1.55 \\
\hline & 187 & 3.48 & 1.56 \\
\hline & 188 & 3.99 & 1.36 \\
\hline & 188 & 3.37 & 1.47 \\
\hline & 189 & 4.01 & 1.19 \\
\hline & 188 & 4.15 & 1.12 \\
\hline & 144 & & \\
\hline Valid N (listwise) & & & \\
\hline
\end{tabular}

Table 4.4 shows that majority of the students agreed that they study hard because they want to have something to be proud of in future mean of $4.30(S D=0.94)$, they like to decide for themselves what gets done and when mean 4.17(SD=0.90) and others have need for new knowledge mean of 4.36(SD=0.96). The students further indicated they do more than required for their study just because they enjoy it mean of 3.93( $S D=1.3)$, do their best at school because they think it will improve their life mean of $4.31(S D=0.98)$ and feels good when busy with school work mean of 4.13( $S D=1.12)$ In addition others were not sure on studying just because they have to mean of 3.06 $(S D=1.6)$, studying hard because of the perception people have on gender mean of 3.37(SD=1.5), studying hard in school because of childhood experiences mean of $3.48(S D=1.6)$ and doing best in school for people to think positively mean of $2.97(S D=1.6)$. Students further agreed that they get a lot of pleasure from school work mean of 3.68( $\mathrm{SD}=1.3)$, successful study depends to a large extent on their efforts mean of $4.40(S D=0.95)$, they do their best at school because they will otherwise have problems mean of $3.75(S D=1.3)$, they do their best at school studies because of positive consequences mean of 4.04(SD=1.22) and that they like to excel in their studies mean of 4.48(SD=0.74). I think that it is very important that I enjoy my studies in my school. Additionally, the respondents also agreed that they are keen to learn more me of 4.28(SD=1.05), school work is an intellectual challenge mean of 3.53(SD=1.51), studies hard because they want a good job marked with good salary mean of $4.00(S D=1.4)$ and because their studies open opportunities to learn about many new things that are of interest mean of 4.00(SD=1.9). They also agreed that they study hard because of self-satisfaction mean of 4.16(SD=1.12). However, the students disagreed that they study hard because of their parents mean of 2.44(SD=1.56). Students strong selfacademic motivation positively contributes to their academic performance.

Table 4.5: Skewness and Kurtosis

\begin{tabular}{|c|c|c|c|c|c|c|c|}
\hline $\mathrm{N}$ & Range & Minimum & Maximum & Mean & Std. Deviation & Skewness & Kurtosis \\
\hline 187 & 4.00 & 1.00 & 5.00 & 4.48 & .74 & -1.84 & \begin{tabular}{l|l} 
& 4.77
\end{tabular} \\
\hline
\end{tabular}


The participants' academic motivation scores were analyzed to get the range, mean, standard deviation, skewness and kurtosis. As shown in Table 4.5, the anticipated minimum and maximum scores were 1 and 5 respectively. The mean score was 4.48 and the standard deviation was 0.74 . The coefficient of skewness was found to be -1.843 meaning that many participants rated themselves highly on this scale. Kurtosis was 4.768 which showed that the distribution was leptokurtic with many values concentrated around the mean. This clearly implies that most of the students scores were above the mean

\subsubsection{Hypothesis Testing}

The null hypothesis stated that there is no significant relationship between academic motivation and academic performance, Pearson product moment correlation coefficient test was used because it measures the strength of linear association between data of two variables. The main assumption underlying this hypothesis was that academic motivation and students' academic performance were independent of each other. In order to test the validity of this claim, data was subjected to a bivariate correlation analysis using the Pearson's product moment correlation co-efficient. In order to test the validity of this claim, a simple regression analysis was run at the .05 level of significance and the results are as shown in tables below.

Table 4.6: Model Summary

\begin{tabular}{|l|l|l|l|l|}
\hline Model & R & R Square & Adjusted R Square & Std. Error of the Estimate \\
\hline 1 & $.65^{\text {a }}$ & .42 & .31 & 1.31 \\
\hline
\end{tabular}

From Table 4.6, it can be seen that there is a strong positive relationship between academic motivation and students' academic performance as depicted by $\mathrm{R}$ of .649. The $\mathrm{R}$ square value also depicts that academic motivation only account for nearly 42.1 percent of the total variance in students' academic performance. Clearly, this implies that the academic motivation can be used as a good predictor to explain academic performance as shown in Table 4.7.

Table 4.7: Analysis of Variance

\begin{tabular}{|l|l|l|l|l|l|l|}
\hline \multicolumn{2}{|l|}{ Model } & $\boldsymbol{s s}$ & $\boldsymbol{d} \boldsymbol{f}$ & $\boldsymbol{M s}$ & $\boldsymbol{f}$ & Sig \\
\hline \multirow{3}{*}{1} & Regression & 144.53 & 23 & 6.28 & 3.67 & $.00^{\mathrm{a}}$ \\
\cline { 2 - 7 } & Residual & 198.46 & 116 & 1.71 & & \\
\cline { 2 - 6 } & Total & 342.99 & 139 & & & \\
\hline \multicolumn{2}{|l|}{ a. Predictors: (Constant), Academic Motivation } & & & \\
\hline \multicolumn{2}{|l|}{ b. Dependent Variable: Academic Performance } \\
\hline
\end{tabular}

In view of the findings, it can be inferred therefore that academic motivation and academic performance were statistically dependent as the p-value in the ANOVA model was .00 which is less than 0.05 , the alpha level of significance. This implies that academic motivation plays a key role in determining academic performance of learners consequently the null hypothesis that stated that there is no significant relationship between academic motivation and academic performance was rejected. Consequently, academic motivation is related to academic performance.

\subsubsection{Discussion of the Results}

This finding supported that of earlier studies by Matthews, et al, (2013), Matuga (2009) and Mutweleli (2010), which reported a positive relationship between students' academic motivation and academic achievement. The samples used in Matuga (2009) and Karsenti \& Thibert (1995) studies, were similar to the one used in the current study in terms of the level of schooling. Thus, irrespective of cross-cultural differences and different study locations, academic motivation was found to be positively correlated to academic achievement. Also a study by Broussard and Garrison as cited by Shkullaku, (2007) who established that academic motivation and academic performance appears to strengthen with age. According to them, by age 9, students with high levels of motivation consistently exhibit higher achievement and class grades than students with low motivation The findings of these studies suggested that students who are 
academically motivated or self-determined to succeed in school were likely to be high academic achievers. However, the findings of the present study did not agree with those reported by Othman and Leng (2011) who focused on primary school pupils and found that the relationship between pupil's academic motivation/self-determination and academic achievement was significant and negative. This implies that the level of schooling may be a significant factor in the measurement of these variables (academic motivation and academic achievement). These study is in agreement with Self-determination theory which put a lot of emphasis on motivation of human beings towards the direction and efforts they choose to bestow upon activities. Motivation is affected by many other factors. Motivation refers to the reason of student engagement in a given activity. Students' difference in motivation levels and types can be a reason for the difference in academic performance among learners. As seen in the study academic motivation is plays a vital role in determining day to day academic performance of a student.

\subsection{Relationship between self-efficacy and academic performance.}

The second objective of this study sought to establish the relationship between self-efficacy and academic performance of students. Various statements in view of self-efficacy were put forth to the respondents in which case they were required to state their levels of agreement on a five-point scale in which 1 represented completely disagree, 2 disagree, 3 not sure, 4 agree and 5 completely agree. Responses from the respondents were analyzed and presented in Table 4.8 .

Table 4.8: Self-efficacy and Academic Performance

\begin{tabular}{|l|l|l|}
\hline $\mathbf{N}$ & Mean & Std. Deviation \\
\hline 189 & 4.25 & .98 \\
\hline 190 & 4.16 & 1.05 \\
\hline 191 & 4.24 & .920 \\
\hline 190 & 4.36 & .99 \\
\hline 187 & 4.09 & 1.07 \\
\hline 189 & 3.66 & 1.42 \\
\hline 188 & 4.21 & 1.07 \\
\hline 191 & 4.26 & 1.06 \\
\hline 191 & 4.23 & .90 \\
\hline 189 & 4.02 & 1.11 \\
\hline 189 & 4.27 & .92 \\
\hline 187 & 4.19 & 1.04 \\
\hline 188 & 4.20 & .10 \\
\hline 189 & 4.32 & 1.09 \\
\hline 189 & 4.38 & 1.11 \\
\hline
\end{tabular}

Table 4.8 shows that majority of the respondents agreed that they are keen to try something complicated mean of 4.25( $S D=0.92)$, try to learn new things when they look difficult mean of 4.16(SD=1.05), do not give up trying something new mean of $4.24(S D=0.92)$, they persist after plans until they make it mean of $4.36(S D=0.99)$ and keep trying if they can't do a job first time mean of $4.09(S D=1.07)$. It was also revealed that majority of the students agreed to the statement that when they have something unpleasant to do, they stick to it until they finish mean of $3.65(S D=1.42)$ and when they decide to do something they go right to work on it mean of 4.21 $(S D=1.07)$. In addition, failure just makes most of the students try harder until they succeed and when they set important goals they usually achieve them mean of $4.26(S D=1.06)$ and 4.23 $(S D=0.90)$ respectively). Most students seemed to be able in dealing with most problems that come their way mean of 4.02 $(S D=1.12)$, felt sure about their ability to do things mean of 4.27( $S D=0.92)$, don't give up on things before completing them mean of $4.19(S D=1.04)$ and that they do not get distracted easily in their work mean of 4.20(SD=0.99). Students also agreed they were self- motivated and don't give up easily mean of $4.32(S D=1.02)$ and $4.38(S D=1.11)$. This clearly implies that self-efficacy plays a vital in academic performance as from the results it evident that those students who understand themselves and their weakness struggle harder to build on them and consequently attains high academic performance. 


\subsubsection{Hypothesis Testing}

The second null hypothesis stated there is no significant relationship between self-efficacy and academic performance. Clearly the assumption that underpinned this statement was that self-efficacy and academic performance were statistically independent. In order to prove the validity of this claim, simple regression analysis using Pearson product moment correlation statistical test was carried out at the .05 level of significance and the results are as shown in Tables 4.9 and 4.10. This test was used because it measures the strength of association between two variables.

\section{Table 4.9: Model Summary}

\begin{tabular}{|l|l|l|l|l|}
\hline Model & R & R Square & Adjusted R Square & $\begin{array}{l}\text { Std. Error of the } \\
\text { Estimate }\end{array}$ \\
\hline 1 & $.37^{\mathrm{a}}$ & .13 & .05 & 1.60 \\
\hline a. Predictors: (Constant), Self-efficacy \\
\hline
\end{tabular}

It can be observed from Table 4.8 that there is a positive relationship between self-efficacy and academic performance $(\mathrm{R}(192)=0.37$. This implies that a unit change in self-efficacy will cause a positive change of .37 units on academic performance. Similarly, R- square value of .14 implies that self-efficacy accounts for about 13.50 percent of the total variance in academic performance in secondary schools. As seen from Table 4.10, the regression model shows that self-efficacy can be used to predict academic performance $(\mathrm{F}=1.66 ; \mathrm{p}$ $\leq .05)$. This implies that academic performance is greatly influenced by self-efficacy and student with high levels of self-efficacy are high academic performers.

Table 4.10: Analysis of Variance

\begin{tabular}{|l|l|l|l|l|l|l|}
\hline \multicolumn{2}{|l|}{ Model } & ss & $\boldsymbol{d f}$ & $\boldsymbol{m s}$ & $\boldsymbol{f}$ & Sig. \\
\hline \multirow{3}{*}{1} & Regression & 64.59 & 15 & 4.31 & 1.67 & $.06^{\mathrm{a}}$ \\
\cline { 2 - 7 } & Residual & 413.96 & 160 & 2.59 & & \\
\cline { 2 - 6 } & Total & 478.55 & 175 & & & \\
\hline \multicolumn{2}{|l|}{ a. Predictors: (Constant), Self-efficacy } & & & \\
\hline
\end{tabular}

In view of the aforesaid finding, it can therefore be concluded that self-efficacy and academic performance are dependent of each other. This is because the p-value for the model was .06 which is more than the acceptable benchmark alpha of .005 , the level of significance. This means that the null hypothesis that stated there is no significant relationship between self-efficacy and academic performance is rejected. Therefore, self-efficacy influences academic performance in public secondary schools.

\subsubsection{Discussion of the Results}

Matuga (2009) reported similar findings in his study of self-regulation, goal orientation, and academic achievement of secondary students in online university courses. The interpretation of this result was that students who had high scores on self-efficacy as measured also had high overall academic achievement score. Similarly, students who had low scores on self-efficacy were found to be low academic achievers. However, the findings of this study did not support earlier findings by Loong (2012) who reported that international students' academic performance, particularly Mathematics performance, was not significantly predicted by self-efficacy. Similarly, Juanita (2008) reported that there were no significant correlations between self-efficacy and academic achievement of middle school students. As highlighted in the literature review, these studies (Loong, 2012 \& Juanita, 2008) did not report the relationship among the various selfefficacy strategies and academic achievement. This relationship was investigated in the current study where the researcher subjected the data to a multiple regression analysis in order to determine the relative predictive weight of self-efficacy on academic achievement.

\subsection{Relative predictive weights of motivation and self-efficacy on academic performance.}

The third objective of the study sought to evaluate the relative predictive weights of motivation and selfefficacy on performance. The null hypothesis was that Motivation and Self-efficacy have no significant 
predictive value on academic performance. Multiple linear regression analysis, which allows the researcher to determine the overall fit of the model and the relative contribution of each of the predictors to the total variables under study, was used as the sstatistical test.

\subsubsection{Hypothesis Testing}

To test this hypothesis, each of the independent variables was first subjected to a simple regression analysis in order to determine their separate predictive values on academic achievement. To begin with, academic motivation scores were analyzed and the results summarized in Table 4.11.

Table 4.11: Beta Coefficients for Academic Motivation

\begin{tabular}{|l|c|c|c|}
\hline & $\begin{array}{l}\text { Standardized } \\
\text { coefficients Beta }\end{array}$ & Sig. & Adjusted R Square \\
\hline Constant & 9.04 & 0.00 & 0.31 \\
\hline $\begin{array}{l}\text { Academic } \\
\text { motivation }\end{array}$ & 0.17 & 0.00 & \\
\hline \multicolumn{2}{|l|}{} \\
\hline
\end{tabular}

From Table 4.11, equation is identified as $\mathrm{Y}=9.04+0.17(\mathrm{AM}) \mathrm{p}<0.05\left(\mathrm{R}^{2}=0.31\right)$. This equation shows that, just like, self-efficacy, academic motivation had a positive and significant predictive value on students' academic achievement $(\beta=0.17, p=0.00)$. The adjusted $\mathrm{R}^{2}$ value of 0.31 implied that (30.70) of the variance in students' academic achievement was due to academic motivation. Students with high academic levels of academic motivation perform highly in school compared to those with low levels of academic motivation.

Further, self-efficacy scores were analyzed to determine the predictive value on academic achievement and the results are summarized in Table 4.12.

Table 4.12: Beta Coefficients for Self-efficacy

\begin{tabular}{|l|l|l|l|}
\hline & $\begin{array}{l}\text { Standardized } \\
\text { coefficients } \\
\text { Beta }\end{array}$ & Sig. & Adjusted R Square \\
\hline Constant & 7.34 & 0.00 & 0.05 \\
\hline Self-efficacy & 0.013 & 0.06 & \\
\hline & & & \\
\hline
\end{tabular}

The resultant simple regression equation from Table 4.12 is given in equation, $\mathrm{Y}=7.337+0.013(\mathrm{SE}) \mathrm{p}<$ $0.05\left(\mathrm{R}^{2}=0.054\right)$. This equation shows that self-efficacy had a positive and significant predictive value on students' academic achievement $(\beta=0.013, \mathrm{p}=0.063)$. The adjusted $\mathrm{R}^{2}$ value of 0.054 suggested that the amount of variation in academic achievement explained by self-efficacy is 5.4 percent.

From Tables 4.11 and 4.12 the resultant equation for predicting academic achievement from academic motivation (AM) and self-efficacy (SE) was significant and therefore the third null hypothesis was therefore rejected. This implied that both self-efficacy and academic motivation had a relative predictive weight on academic performance with each playing a vital role in predicting academic performance of an individual at any given time.

\subsubsection{Discussion of the Results}

These finding contradicted those of an earlier study by Loong (2012), who reported that compared with other factors; self-efficacy was not a significant predictor of academic achievement. Further, Downing \& Ning (2010) found that students' motivation was the strongest predictor of academic performance compared 
to other variables studied. However, the findings of the current study supported those reported by Al Khatib (2010), Habte (1997) and Gemeda, (1996). These researchers found that self-efficacy was the stronger predictor of students' academic achievement as compared to academic motivation. This means that students who are academically motivated and use self-efficacy are likely to be high academic achievers since Kitsantas (2002) noted that the interplay between academic motivation and self-efficacy is important in promoting academic achievement. The study is in agreement with Bandura social learning theory and selfdetermination theory which attributes academic motivation and self-efficacy as essentials determinants of success in every activity. It is influential factor of whether individuals will be able to put efforts on a task and cope with a difficult situation. From these study individuals with high levels of self-efficacy and academic motivation are perceived as high performers.

\subsection{Gender difference in academic motivation and self-efficacy.}

The fourth objective sought to test for gender difference in academic motivation and self-efficacy. The participants' gender academic motivation scores were analyzed in order to find the mean and standard deviation and the results are summarized in Table 4.13.

Table 4.13: Gender differences in Academic Motivation

\begin{tabular}{|l|l|l|l|l|}
\hline & Gender & N & Mean & Standard Deviation \\
\hline Academic Motivation & Boys & 94 & 3.96 & 1.19 \\
\cline { 2 - 5 } & Girls & 97 & 3.69 & 1.28 \\
\hline
\end{tabular}

$\mathrm{n}=191$

Results in Table 4.13 show that the mean academic motivation score was 3.96 and 3.69 for boys and girls respectively. Thus, in terms of academic motivation, boys had a relatively higher mean score than girls. This implies that male students have high level of academic motivation compared to their female counterparts.

The participants' gender self-efficacy scores were analyzed in order to find the mean and standard deviation and the results are presented in Table 4.14.

Table 4.14: Gender differences in Self-efficacy

\begin{tabular}{|l|l|l|l|l|}
\hline Self-efficacy & Gender & N & Mean & $\begin{array}{l}\text { Standard } \\
\text { Deviation }\end{array}$ \\
\hline & Boys & 94 & 4.26 & 1.02 \\
\cline { 2 - 5 } & Girls & 97 & 4.12 & 1.05 \\
\hline & $\mathrm{n}=191$ & & & \\
\hline
\end{tabular}

Results in Table 4.14 show that the mean self-efficacy score for boys (4.26) was higher than for girls (4.12). In reference to the fourth objective of the study which was to test if there are gender differences in students' academic motivation and self-efficacy, the fourth null hypothesis stated that there is no Gender difference in academic motivation and self-efficacy.

\subsubsection{Hypothesis Testing}

To test this hypothesis, two supplementary null hypotheses were advanced. These were;

$\mathrm{H}_{04.1:}$ There are no gender differences in students' academic motivation.

$\mathrm{H}_{04.2 \text { : }}$ There are no gender differences in students' self-efficacy.

To test the first null hypothesis, data obtained with regard to the respondents' academic motivation was subjected to independent samples t-test. The results are presented in Table 4.15.

Table 4.15: Independent Samples t-test for gender differences in Academic Motivation

\begin{tabular}{|l|l|l|l|}
\hline Variable & $\boldsymbol{t}$ & $\boldsymbol{d f}$ & Sig.(2-tailed) \\
\hline Academic Motivation & -1.67 & 19 & 0.05 \\
\hline
\end{tabular}


Results in Table 4.15 show that there were significant gender differences in academic motivation between boys and girls $(\mathrm{t}=-1.168$, $\mathrm{df}=192, \mathrm{P}<0.05)$, and this difference was in favor of boys. The first supplementary null hypothesis was therefore rejected. Compared to girls, boys were found to be more academically motivated and self-determined. As a result of the finding boys were found to perform better academically as compared to girls due to high levels of academic motivation. High levels of academic motivation can be equated to high academic performance of the learner.

The current study findings on gender differences in domains of academic motivation contradicted the findings of an earlier study done by Barkoukisa, et al, (2008) who found that there were gender differences regarding intrinsic motivation to know and amotivation. More specifically, females were higher in intrinsic motivation to know. Further, the findings of the present study did not support earlier findings by Gilles and Karsenti (1996) who reported that girls were lower in amotivation compared to boys. Contrary, to the findings of this study, Rusilo and Arias (2004), reported that girls had lower levels of extrinsic motivation compared to boys.

In most of the studies reviewed, girls were found to be more self-determined or either more intrinsically motivated or less extrinsically motivated compared to boys. The present study provided conflicting results and one possible reason that may help to explain the observed contradictions is the cross-cultural differences in the way of upbringing boys and girls in developed and developing countries. It is worth noting that all the previous studies cited were done in developed countries and no doubt the day to day schooling and home experiences of adolescents in these countries is different from what their counterparts in developing countries experience.

The second supplementary null hypothesis (in line with objective four) was stated in order to help in determining whether there existed any gender differences with regard to student's self-efficacy. The hypothesis was stated as: there are no gender differences in students' self-efficacy. To test this hypothesis, the self-efficacy scores were analyzed by use of independent samples t-test and the results presented in Table 4.16.

Table 4.16: Independent Samples t-test for gender differences in Self-efficacy

\begin{tabular}{|l|l|l|l|}
\hline Variable & $\boldsymbol{t}$ & $\boldsymbol{d} \boldsymbol{f}$ & Sig.(2-tailed) \\
\hline Academic Motivation & -0.107 & 192 & 0.05 \\
\hline
\end{tabular}

From Table 4.16 it was observed that there was a significant gender difference in the overall self-efficacy mean scores $(\mathrm{t}=-0.107, \mathrm{df}=192, \mathrm{p}<0.05)$ and this difference was in favour of boys. The second supplementary null hypothesis was therefore rejected. Boys were found to have high levels of self-efficacy compared to girls. This implies that boys have high levels of self-efficacy thus high academic performers and consequently high levels of self-efficacy can be equated to high academic performers.

\subsubsection{Discussion of the Results}

Boys were found to have high levels of self-efficacy compared to girls implying that boys have high levels of self-efficacy consequently high academic performance and consequently high levels of self-efficacy can be equated to high academic achievement. These findings were similar to those reported in Ethiopia by Habte (1997) and Gemeda (1996). However, a common observation in these two studies is that they never reported if there were gender differences in the various self-efficacy strategies. The results in the current study show that there were significant gender differences with respect to all the self-efficacy strategies and these differences were in favour of boys except the learning strategy on seeking assistance where the difference was in favour of girls. These findings differ with earlier findings by Al asmari and Ismail (2012) and, Zimmerman and Martinez-Pons (1989) which reported that girls were found to have made more use of self-efficacy learning strategies than boys. The study revealed that practical implication of programs designed to improve the academic self-efficacy of girls is needed, especially for female adults. This study is in agreement with both Self-determination Theory (SDT) by Ryan and Deci and Social Learning Theory by Bandura in that the findings inferred that self-efficacy; academic motivation and academic performance are statistically dependent. 


\section{Summary, Conclusions And Recommendations \\ 5.1 Introduction}

This chapter discusses the findings of the study in relation to the objectives of the study and gives the interpretation thereof in view of other research findings based on empirical literature. The chapter is divided into four sections. The first section summarizes the findings of the study, the second section shows the implications of the findings, the third section is where conclusions are drawn based on the findings and finally the fourth section gives the study recommendations for policy and further research.

\subsection{Summary}

The study was designed to investigate academic motivation and self-efficacy as determiners of academic performance of secondary school students in Kitui County. The study also explored if there were significant gender differences in students' academic motivation and self-efficacy. In the exploratory part of the study, levels of academic motivation, self-efficacy, regression weights for academic motivation and self-efficacy were studied. However, the ultimate goal of the study was to identify the model for predicting students' academic achievement from academic motivation and self-efficacy.

The first objective of the study was to determine the relationship between academic motivation and academic achievement. Empirical evidence for the existence of a significant and positive relationship between students' academic motivation and academic achievement was provided. Further analysis revealed that academic motivation was significantly and positively predicted students' academic achievement. Those students with high levels of academic motivation perform well in their academics compared to those with lower levels of academic motivation

The second objective of the study was to investigate the relationship between self-efficacy and academic achievement. It was found that self-efficacy had a positive and significant relationship with students' academic achievement. The third objective of the study was to establish the relative predictive weights of academic achievement from academic motivation and self-efficacy learning. Given the two main predictor variables in the study, that is, academic motivation (AM) and self-efficacy learning a significant prediction weight was found with self-efficacy being the better predictor of students' academic achievement. The fourth objective of the study was to test if there were gender differences in students' academic motivation and self-efficacy. Significant differences were detected in the two variables and these differences were in favour of boys. With regard to self-efficacy learning, significant gender differences were observed on the overall self-efficacy learning mean scores and this difference was in favour of boys.

\subsection{Conclusions}

The results of this study presented some evidence of the existence of the hypothesized relationship between academic motivation; self-efficacy learning and academic performance. From table 4.4 we can establish that academic motivation have a positive and significant relationship with students' academic performance. With regard to academic motivation, teachers and parents should devise ways of arousing students' interest in academics by showing the relevance of secondary school education in their lives and giving students' feedback in order to raise their expectancy for success. This will help in nurturing the students' academic motivation towards accomplishment which was found to have significant and positive influence on academic performance(Mutweleli, 2014) .

From table 4.17 it can therefore be concluded that self-efficacy and academic performance are dependent of each other it is evident that those students who understand themselves and their weakness struggle harder to build on them and consequently attains high academic performance.

Generally, given that these two constructs (academic motivation and self-efficacy) were found to have a significant positive influence on academic achievement, there is need for development of interventional programs in schools targeting girls. These programmes should gear towards boosting girls' academic motivation and use of self-efficacy learning strategies. A conducive learning environment should also be provided for girls in order to enhance and improve their academic motivation and level of self-efficacy.

Generally, a major conclusion of the results of this study is that, teaching learners (regardless of gender) to self-regulate and enhance their motivational beliefs might serve to increase their academic achievement. The study showed that gender is one of the factors that may account for differences in students' academic 
motivation and self-efficacy. This is because significant gender differences were found with regard to these two variables. Boys were found to be better than girls in academic motivation and self-efficacy learning strategies

From the objective on relative predictive weights of motivation and self-efficacy on academic performance Self-efficacy learning was found to be a better predictor of students' academic achievement as compared to academic motivation. However, the two variables combined accounted for more variance in predicting academic achievement as compared to when each variable was studied individually. Thus, the two variables should be seen as complementary and therefore students should be helped in order to improve their academic performances. Parents and teachers should aim at creating a conducive home and school learning environments which will help students to develop appropriate self-regulated learning strategies. More specifically, students should be guided in the development of self-regulated learning strategies which were found to have a positive and significant influence on academic performance.

\subsection{Policy Recommendations}

Based on the findings of the study, the following recommendations were made:

i. Since academic motivation and self-efficacy were found to have positive and significant influence on students' academic performance, teachers, parents and all the stakeholders in education should work together in creating conducive school and home environments for fostering the development of these constructs in learners. More specifically, the development of the different types of academic motivation and self-efficacy learning strategies found to have a positive predictive value on academic performance should be emphasized.

ii. Appropriate intervention programmes should be developed in schools, particularly targeting girls in order to help reduce the gender differences which were found to exist with regard to students' academic motivation and self-efficacy learning.

\subsection{Recommendations for Further Research}

This study established the relationship between academic motivation and self-efficacy on academic performance among form three students teachers in Kitui County.

For further research in line with this study the researcher recommends;

1. A similar study could be conducted in other parts of the country so as to compare the possible school and home environmental determinants of motivation and self-efficacy as far the objective on the relationship between academic motivation and self-efficacy is concerned

2. The results of this study should not be generalized to the whole Kenyan school population because it involved a small sample drawn from only one county. In order to clearly understands academic motivation and self-efficacy as predictors of academic performance, the research should be replicated to cover a larger sample drawn from all over the country and include form one to form four.

3. These findings on Gender difference in academic motivation and self-efficacy contradict those of many other researchers in that these studies never reported if there were gender differences in the various self-efficacy strategies as cited in chapter two thus additional studies on this area are necessary because research findings on academic motivation and self-efficacy as predictors of academic performance especially on areas of Gender difference in academic motivation and selfefficacy are still inconclusive.

4. There is need to carry out a well-controlled experimental research on the relationship between academic motivation, self-efficacy and academic performance because of the likelihood of the presence of uncontrolled influences/extraneous variables, which may have had an influence on the findings of this study which attributed self-efficacy and academic motivation as strong determinants of academic performance of a learner. 


\section{References}

1. Abdelaziz S. N., Alsawaie, D. S., \& Tibi, M.A. (2012). Predicting Mathematics Achievement By Motivation and Self-efficacy across Gender and Achievement Levels Interdisciplinary Journal of Teaching and Learning Volume 2, Number 2 summer 2012 United Arab Emirates University

2. Arouson D., \& Barrow 1. Sander W. (2007). Teacher and Student Achievement in Chicago public high school labor. Econ.25 (1):95-135.

3. Ary D., Jacobs C. L., Razavieh A., \& Sorensen C. (2009). Introduction to Research in Education (8 ${ }^{\text {th }}$ Edition). Cengage Learning, Inc, Canada.

4. Ajayi K.O., Lawami. A.O., \& Salomi, M.O. (2012) The Influence of Self-concept and Academic Motivation on Students' Attitude to Mathematics in selected secondary schools in Ogun State, Nigeria. European journal of scientific Research, 67 (3), 444-455

5. Aremu, J., \& Sokan, D. (2003). Journal of Educational Psychology 99 (4), 734-736

6. Bandura, A. (1997). Self-efficacy: The exercise of control. New York: Freeman.

7. Barkoukis, V., Tsorbatzoudis, H., Grouios, G., \& Sideridis G. (2008). The assessment of intrinsic and extrinsic motivation and amotivation: Validity and reliability of the Greek version of the Academic Motivation Scale. Assessment in Education: Principles, Policy \& Practice, $\quad 15(1), \quad 39$ 55

8. Bell,J \& Bryman .(2003). Doing your research project. Buckingham; Open University

9. Chopin,S.M.,Danish,S.J.,Seers, A. \& Hook ,J.N. (2012),Effects of Mentoring on thedevelopment of leadership Self efficacy and Political skill. J Leadership studies 6:17-32.Doi:10.1002/jls.21253

10. Chowdhury, S.M., \&Shabuddin M.A. (2007). Self-efficacy, Motivation and their Relationship to academic performance of Bangladesh college students. College quarters, 10(1)

11. Flood, M. (2012). Mentoring and self-efficacy in Female Undergraduate Business students. Retrieved from http://etd.ohiolink/on 4th September 2016.

12. Florentina, N. (2015). Influence of e-mentoring on self-esteem, self-efficacy and academic achievement of secondary school girls in Nairobi and Kiambu counties. (Unpublished doctoral dissertation). Kenyatta University, Nairobi, Kenya.

13. Gagne, M., \& Deci,E.1 (2005). Self -determination theory and work motivation. Journal of organizational behavior, Maiden 26, 331-362.

14. Gall, J. Borg. W. \& Gall. (1997). Educational research an introduction. (6 ${ }^{\text {th }}$ ed.). New York: Longman

15. Gilles, T., \& Karsenti, P.T. (1996). Motivation Profile of adolescent boys and girls: Gender Difference throughout Schooling .Retrieved from http://www.eric/ed..gov/contentdelivery/servlet/ERICSservlet.

16. Jerome, M.K. (2015). Influence of home environment on academic performance of students in public secondary schools in Kitui county, Kenya. (Unpublished master's thesis) South Eastern University College, Nairobi.

17. Kathryn, K. M. (2013). Predictors of students' academic performance.Kenya Journal of educational planning, Economics and management 60, (1), (2).

18. K.C.S.E Examination essentials statistics (2014\& 2015) Retrieved on October 2016 at url;http;//capitalfm.co.ke/news/downloads. $\quad$ /kcse_2014/appendix\%20A201220K.C.S.E\%20 Examination\%20 ESSENTIAL\%STATISTICS.PDF

19. Kothari, C.R. (2005). Research methodology, methods and techniques, New Delhi, Wiley Eastern limited.

20. Kwena,J.S.A.(2007).An investigation into selected factors on academic self-concept among primary school pupils in Bondo district.(unpublished Doctoral thesis).Kenyatta university, Nairobi.

21. Mathews, R.A. Hoessler C., Jonker I., \& Stockley D. (2013). Academic motivation in calculus. Canadian Journal of sciences, mathematics and technology.139101-17. Retrieved from http;/www.Tandfonline.com/doi/pdf/10.1080/14926156.on $3^{\text {rd }}$ September 2016

22. Mugenda, A. G., \& Mugenda, O.M (2007). Research methods qualitative and quantitative approaches. Nairobi; Acts press, revised edition. 
23. Mutweleli, S. M. (2014). Academic motivation and self-regulated learning as predictors of Academic achievement of students in public secondary schools in Nairobi County, Kenya.

(Unpublished doctoral dissertation). Kenyatta university, Nairobi. Kenya.

24. Mwangi, C.N. (2015) Predictors of academic resilience and its relationship to academic Achievements among secondary school students in Kiambu county Kenya, (unpublished doctoral dissertation), Kenyatta university, Nairobi. Kenya.

25. Othman, N., Leng, B. K (2011). The relationship between self-concept intrinsic motivations, self Determination and Academic achievement among Chinese primary school students. International Journal of Psychological Studies, 3(1).

26. Peterson, 1., \& Soughs, J. N. (2011). The difference between retained and promoted children in educational services received. Journal of Psychology in Africa ,86(4) ,764-806

27. Ryan, M. R. \& Deci, E. L., (2000). Intrinsic and extrinsic motivations: Classic, Definitions andNew directions. Contemporary Educational Psychology, 25,

28. Shkullaku, R. (2007). The Relationship between Self efficacy and Academic Performance in the Context of Gender among Albanian Students European. (unpublished master's thesis) University of Tirana, Alban.

29. Simiyu, M.G. (2010). Influence of test anxiety and self-efficacy on Mathematics performances of secondary school students in Kanduyi, division of Bungoma Sub county. (Unpublished master thesis), Kenyatta university, Nairobi.

30. Siringi,S.(2011).Revealed: Kenya's $\quad$ worst $\quad$ schools.Retrieved from http://www.nation.co.ke/news/Revealed. + Kenyans. Worst $=$ schools+//1056./1119328/-item/0/-/5 dots9z/- /index .html

31. Vance, D. (2012). Self-efficacy and ministerial Field Education; An instructional Design perspective. Faculty of Virginia polytechnic institute and state university retrieved from http://scholar.lib.vt.edu/theses/10 Dec 2016.

32. Yachew, A.T. (2013). Relationship between self-efficacy, academic achievement and gender in Analytic chemistry at Debres Markos College of teacher education, (unpublished master thesis).

Debres Markos, Ethiopia. 